\title{
FAKTOR INTERNAL DAN EKSTERNAL DALAM PENGEMBANGAN NILAI EKONOMI KOPI CODOT DI HKm BERINGIN JAYA, KABUPATEN TANGGAMUS
}

\author{
Internal And External Factors in Developing Economic Value of Codot Coffee in HKm Beringin \\ Jaya, District of Tanggamus
}

\section{Bella Audia*, Hari Kaskoyo, Christine Wulandari dan Rahmat Safe`i}

Jurusan Kehutanan, Fakultas Pertanian, Universitas Lampung

JIn, Prof. Dr. Soemantri Brojonegoro No. 1 Gedung Meneng, Bandar Lampung

*Email: bellaaudia23@gmail.com

\begin{abstract}
Codot coffee is robusta coffee which is eaten by codot (bat) and can be developed to increase farmers' income. The purpose of the research is to identify internal and external factors towards raising of the economic value of codot coffee. Data retrieval is done by interviewing HKm Beringin Jaya farmers and Himawari Farmers Group, observation, and documentation study. Data was analyzed by descriptively qualitative. The results showed internal factors that influence of the economic value of codot coffee, namely: 1) the suitability of geographical location, 2) very affordable accessibility, 3) good quality of codot coffee, 4) production technology already supports, 5) knowledge of the benefits of less codot coffee, and 6) shade of coffee plants is still lacking. Influence external factors, namely: 1) the rapid development of codot coffee demand, 2) the rapid development of information and communication technology, 3) the business partners outside district of Tanggamus, 4) the stable price of codot coffee, 5) the uncertainty of weather effects, and 6) various competitors from other types of coffee. Extension education is needed to increase knowledge about the benefits and advantages of codot coffee; in addition partnerships with other private sectors need to be developed to improve marketing.
\end{abstract}

Keywords: community forestry, codot coffee, farmers' income

\section{ABSTRAK}

Kopi codot merupakan kopi jenis robusta yang dimakan oleh codot (kelelawar) dan dapat ditingkatkan untuk menambah pendapatan petani. Tujuan penelitian untuk mengidentifikasi faktor internal dan eksternal terhadap pengembangan nilai ekonomi kopi codot. Pengambilan data dilakukan dengan wawancara terhadap petani HKm Beringin Jaya dan Kelompok Wanita Tani Himawari, observasi, dan studi dokumentasi. Data yang diperoleh dianalisis secara deskriptif kualitatif. Hasil penelitian menunjukkan faktor-faktor internal yang berpengaruh terhadap nilai ekonomi kopi codot, yaitu: 1) sesuainya lokasi geografis, 2) aksesibilitas yang sangat terjangkau, 3) baiknya kualitas kopi codot, 4) teknologi produksi yang sudah mendukung, 5) pengetahuan manfaat kopi codot yang kurang, dan 6) naungan tanaman kopi masih kurang. Faktor-faktor eksternal yang mempengaruhi, yaitu: 1) pesatnya perkembangan permintaan kopi codot, 2) pesatnya perkembangan teknologi informasi dan komunikasi, 3) banyaknya mitra usaha diluar Kabupaten Tanggamus, 4) stabilnya harga kopi codot, 5) ketidakpastian pengaruh cuaca, dan 6) berbagai kompetitor dari jenis kopi lain. Penyuluhan perlu dilakukan untuk menambah pengetahuan tentang manfaat dan keuntungan 
Jurnal Belantara Vol. 2, No. 2, Agustus 2019 (142-148)

kopi codot; selain itu kemitraan dengan pihak sektor lainnya perlu dikembangkan untuk meningkatkan pemasaran.

Kata kunci: hutan kemasyarakatan, kopi codot, pendapatan petani

\section{PENDAHULUAN}

Hutan kemasyarakatan adalah hutan milik negara yang dikelola oleh masyarakat dengan tetap menjaga kelestarian Kaskoyo et al., (2017); Wulandari \& Inoue (2018) dan memenuhi keadaan sosial dan ekonomi masyarakat. Oleh karena itu persoalan ekonomi dan sosial menjadi sasaran pemerintah dalam memberikan izin kepada masyarakat untuk mengelola hutan (Kementerian Lingkungan Hidup dan Kehutanan, 2016). Pengelolaan areal kerja HKm dilakukan dengan memadukan berbagai jenis tanaman atau agroforestri, yang merupakan sistem kompleks terjadi antara manusia dengan sumberdaya alam yang dapat mengatasi masalah ekonomi yang berkembang di masyarakat sekitar hutan (Yuwariah, 2015). Hal tersebut didukung oleh Wulandari (2011); Wulandari et al. (2014); Febryano (2008); \& Febryano et al. (2009) bahwa lahan hutan dapat bermanfaat secara optimal untuk masyarakat jika pengelolaannya dilakukan menggunakan pola agroforestri.

Sejalan dengan perubahan zaman, tehnik agroforestri menjadi salah satu faktor pendukung dalam perkembangan ekonomi. Menurut Saragih (2010) program pengembangan usaha tani dengan sistem agroforestri bertujuan mengarahkan masyarakat atau petani secara produktif dan efisien untuk menghasilkan berbagai produk yang memiliki nilai tambah dan daya saing yang tinggi, baik di pasar domestik maupun pasar internasional. Salah satu jenis tanaman yang dikembangkan di lahan hutan dengan sistem agroforestri adalah kopi. Menurut Mbow et al. (2014) kopi termasuk hasil pertanian yang dapat membantu keadaan perekonomian masyarakat.

Kopi codot merupakan kopi jenis robusta yang dimakan oleh kelelawar atau codot, lalu dimuntahkan kembali dan jatuh di bawah tanaman kopi. Biji kopi bekas kunyahan codot tersebut dikumpulkan oleh petani. Buah kopi yang dimakan codot adalah buah yang berwarna merah, sehingga kopi codot ini memiliki kualitas yang baik. Saat ini potensi yang ada pada kopi codot belum sepenuhnya dimanfaatkan secara optimal oleh petani. Tujuan dari penelitian ini adalah untuk mengetahui faktor internal dan eksternal dalam pengembangan nilai ekonomi kopi codot.

\section{METODE}

Penelitian ini dilakukan di Hutan Kemasyarakatan $(\mathrm{HKm})$ Beringin Jaya yang berada pada areal Kesatuan Pengelolaan Hutan (KPH) Kota Agung Utara, Kabupaten Tanggamus, Provinsi Lampung pada bulan November-Desember 2018. Data primer didapat melalui wawancara secara langsung dengan responden yaitu petani dan KWT Himawari yang mengelola kopi codot. Data sekunder didapat dari literatur yang berkaitan dengan topik penelitian. Responden sebanyak 42 orang petani (dari total petani 561 orang) yang diperoleh melalui Rumus Slovin. Selanjutnya dilakukan analisis data kualitatif terhadap faktor internal dan eksternal, seperti: kekuatan, kelemahan, peluang, dan ancaman dalam pengembangan nilai ekonomi kopi codot. 
Jurnal Belantara Vol. 2, No. 2, Agustus 2019 (142-148)

\section{HASIL dan PEMBAHASAN}

\section{A. Faktor Internal Pengembangan Nilai Ekonomi Kopi Codot}

\section{A.1. Kekuatan}

\section{Lokasi geografis yang sesuai untuk tanaman kopi}

Letak geografis Hkm Beringin Jaya berada di ketinggian antara 500 mdpl sampai dengan $1.000 \mathrm{mdpl}$, dengan topografi berbukit, temperatur udara berkisar antara $22^{\circ} \mathrm{C}$ sampai $28^{\circ} \mathrm{C}$ menjadi kondisi yang cocok untuk pengembangan kopi robusta. Hal tersebut sejalan dengan Nurlaeli (2018) yang menjelaskan bahwa ketinggian lereng gunung yang berkisar 1.000 mdpl cocok untuk pengembangan tanaman kopi. Jika hasil panen melimpah maka ketersediaan buah kopi untuk dimakan codot tidak berkurang dan dapat dimanfaatkan oleh petani pengumpul kopi codot untuk dijual. Hairiah \& Ashari (2013) menyatakan bahwa agroforestri berbasis kopi memiliki peran sebagai pendukung untuk meningkatkan pendapatan petani, serta berperan dalam konservasi tanah dan penambahan cadangan karbon.

\section{Aksesibilitas yang mudah}

Jalur transportasi di Kecamatan Sumberejo dalam kondisi baik sehingga mempermudah mobilitas penduduk dalam memasarkan hasil usaha pertaniannya. Kelompok-kelompok HKm yang berada di Register 30 Gunung Tanggamus meliputi kelompok yang berada pada dua kecamatan yaitu Kecamatan Sumberejo dan Kecamatan Pulau Panggung. Hal ini menjadi keuntungan tersendiri bagi masyarakat terutama KWT Himawari dalam memasarkan atau mempromosikan kopi codot. Sesuai dengan pendapat Abdulhaji \& Yusuf (2016) bahwa pengaruh aksesibilitas merupakan hal yang sangat penting untuk kemajuan usaha yang ada di wilayah tersebut serta mendukung fasilitas baru di masa mendatang.

\section{Kualitas kopi yang baik}

Kualitas kopi codot terbentuk berasal dari biji kopi merah bekas kunyahan codot. Kualitas kopi codot juga didukung dengan persyaratan yang ada di KWT Himawari yaitu kualitas fisik biji kopi harus baik dengan tingkat kekeringan (kadar air) di bawah 14\%, dengan cacat yang sangat sedikit. Menurut Diwangkoro (2017) kualitas kopi yang baik berasal dari kualitas biji kopi dan cara pengolahannya; dimana hal tersebut sangat berpengaruh terhadap citarasa yang dihasilkan dan kepuasan konsumen. Studi yang dilakukan Joko et al. (2009) menunjukkan bagaimana kualitas kopi sangat ditentukan oleh matangnya kopi yang menghasilkan citarasa dan aroma yang berbeda.

Biji kopi codot yang diterima oleh KWT Himawari dari petani berupa biji kopi kering dan basah. Biji kopi yang masih basah langsung dibersihkan lalu dijemur, setelah kering jika ada pemesanan maka biji kopi langsung di-roasting menggunakan roaster. Biji di-roasting sesuai karakter kopi masing masing, mulai dari high - medium - medium to dark. Biji kopi yang sudah di roasting didiamkan kurang lebih selama 12 jam. Biji yang sudah di roasting tidak semuanya langsung digiling menjadi bubuk melainkan disimpan di toples. Jika ada pemesanan produk dalam bentuk kopi bubuk, maka kopi yang sudah di-roasting baru akan digiling menjadi bubuk menggunakan mesin grinder. Setelah di-roasting kopi didiamkan 24 jam dan kemudian masuk tahapan pengujian citarasa atau cupping test untuk menjaga konsistensi rasa kopi. Selanjutnya masuk pada tahap terakhir, yaitu tahap pengemasan produk (packing).

\section{Teknologi produksi yang baik}

Produksi yang dilakukan KWT Himawari didukung oleh adanya beberapa mesin modern yang didapat dari bantuan Bank Indonesia (BI) sejak bulan Desember tahun 2016. Mesin 
tersebut berupa hiller (mesin penggiling untuk memisahkan kulit tanduk dan biji), mesin grinder (mesin penggiling menjadi bubuk), dan mesin roasting (mesin penyangraian kopi). Ketiganya didapatkan secara gratis dalam program "Bantuan Peralatan Produksi Pasca Panen Kopi". Bantuan diberikan langsung kepada KWT Himawari setelah melalui tahap survey dan diskusi dari pihak BI. Bantuan mesin tersebut memberikan nilai tambah dalam menghasilkan kualitas produk kopi dan dapat menghemat waktu dalam proses produksi jika dibandingkan dengan metode konvensional. Diwangkoro (2017); Joko et al. (2009) berpendapat bahwa dukungan teknologi produksi dapat membantu menghasilkan suatu produk yang kualitasnya lebih baik.

\section{A.2 Kelemahan}

\section{Kurangnya pengetahuan manfaat kopi codot}

Manfaat kopi codot sampai saat ini belum dapat diketahui secara spesifik, karena kopi codot belum sampai kepada tahap uji laboratorium. Pengenalan manfaat kopi codot juga belum banyak diberikan melalui penyuluhan. Sebanyak 7 orang dari 42 responden yang pernah mendapatkan penyuluhan dari KWT Himawari dan Kelompok Tani Beringin tentang kopi codot, sementara dari pihak lain memberikan penyuluhan tentang kopi petik biasa. Kurangnya pengenalan dan sosialisasi tentang kopi codot kepada petani berdampak pada kurangnya pengetahuan, manfaat dan nilai tambah atau keuntungan yang bisa didapat. Penyuluhan yang tepat akan mempengaruhi kinerja petani dalam mengelola lahan

2. Kurangnya naungan pada tanaman kopi

Lahan HKm Beringin Jaya didominasi oleh tanaman kopi dan memiliki sedikit pohon penaung. Hanya 1 orang dari 42 responden yang memiliki paling banyak jumlah pohon penaung yaitu 13 pohon, dan ada 4 orang yang memiliki pohon penaung paling sedikit yaitu 2 pohon, selebihnya ada 14 orang yang memiliki 4 pohon penaung dalam 1 hektar. Sedikitnya jumlah pohon penaung tersebut disebabkan oleh illegal logging yang terjadi pada tahun 2000an, sehingga pohon penaung di lahan HKm Beringin Jaya hampir tidak ada.

Kurangnya jumlah pohon penaung yang ada di HKm Beringin Jaya dapat berpengaruh terhadap kopi codot. Jika jumlah pohon penaung hanya sedikit, maka jumlah codot yang berada di $\mathrm{HKm}$ Beringin Jaya juga sedikit, karena tidak adanya tempat tinggal bagi codot. Pohon penaung yang biasa ditanam petani adalah lamtoro (Leucaena sp.). Sedikitnya pohon penaung membuat lokasi tersebut juga rentan terhadap bencana alam, seperti: banjir, longsor, dan erosi. Selain dapat berfungsi untuk mencegah sinar matahari secara langsung ke tanaman kopi, Sakiroh et al. (2013) menyatakan bahwa pohon penaung juga dapat berfungsi sebagai sumber bahan organik yaitu dari serasah daunnya.

Tanaman kopi pada dasarnya memerlukan cahaya yang cukup sehingga banyak ditanam dengan sistem agroforestri. Menurut ling et al. (2012) jenis pohon penaung mempengaruhi jumlah intensitas cahaya matahari yang dapat diserap tanaman kopi. Oleh karena itu penggunaan berbagai jenis pohon penaung akan mempengaruhi pertumbuhan, produksi, dan mutu kopi yang dihasilkan. Menurut Saragih (2010) sistem multistrata merupakan sistem terbaik yang dapat berfungsi untuk konservasi tanah yang dapat mengurangi terjadinya degradasi lahan seperti erosi serta dapat menjaga kelembaban tanah dan udara.

\section{B. Faktor Eksternal Pengembangan Nilai Ekonomi Kopi Codot}

\section{B.1 Peluang}

\section{Perkembangan permintaan kopi codot yang pesat}

Peningkatan permintaan kopi codot cukup baik dengan perkembangan terhitung sejak bulan Maret 2017 sampai tahun 2018. Permintaan pasar dan respon konsumen yang cukup baik menjadi peluang untuk berkembangnya kopi codot. Permintaan kopi codot yang cukup 
tinggi juga dapat menjadi peluang dalam pemasaran yang lebih luas baik dalam maupun luar negeri. Sesuai dengan penelitian Supriatna \& Aminah (2014) bahwa permintaan kopi oleh pihak konsumen sangat mempengaruhi sistem pemasaran yang akan dijalankan ke depannya, serta bagaimana strategi pemasaran yang akan dilakukan.

\section{Perkembangan teknologi informasi dan komunikasi yang pesat}

Pemasaran kopi codot di HKm Beringin Jaya sampai saat ini masih banyak dilakukan secara konvensional yaitu dengan bekerjasama oleh beberapa pihak seperti reseller, dan menawarkan secara langsung kepada konsumen akhir. Penelitian Sitanggang \& Sembiring (2013) menunjukkan bahwa penggunaan media sosial harus dilakukan secara optimal agar produk kopi codot dapat dikenal lebih luas oleh konsumen dari dalam maupun luar negeri. Kemajuan zaman diikuti dengan kemajuan teknologi yang semakin canggih dapat membantu kehidupan manusia. Aplikasi media sosial saat ini banyak dimanfaatkan dalam mempromosikan berbagai macam usaha di bidang ekonomi kreatif maupun dibidang lainnya. Media sosial seperti Facebook dan Instagram juga digunakan oleh KWT Himawari dalam memasarkan produk kopi codot, namun penggunaan aplikasi tersebut belum dilakukan secara optimal. Menurut Incamilla et al. (2015) perkembangan teknologi dan Informasi menjadi pendukung generasi yang akan datang serta menjadi pendukung dalam pemasaran suatu produk yang lebih luas.

3. Mitra usaha di luar Kabupaten Tanggamus yang cukup banyak

Ada beberapa lembaga atau instansi yang membantu memasarkan produk yang dihasilkan oleh KWT Himawari, yaitu: KORUT (Konsorsium Kota Agung Utara), HKm Mart Bandar Lampung, Pesona Mart Kabupaten Tanggamus, BUPSHA (Bina Usaha Perhutanan Sosial dan Hutan Adat), Kodim (Komando Distrik Militer) Tanggamus, dan TFCA (Tropical Forest Conservation Act) Sumatera. KWT Himawari bermitra dengan beberapa lembaga atau instansi di luar Kabupaten Tanggamus yang bersifat sementara dalam mengembangkan produk kopi codot. Mitra usaha terkait pemasaran kopi codot belum ada yang menjadi mitra tetap. Menurut Nalurita et al. (2014) mitra tetap adalah suatu lembaga atau instansi yang bekerja sama dan saling mendapatkan keuntungan. Penelitian Sarma (2014) memperlihatkan bagaimana terjalinnya kemitraan dapat mengoptimalkan strategi pemasaran produk dalam dunia usaha pertanian yang dapat mendukung meningkatkan pendapatan petani. Kemitraan juga berpengaruh terhadap ketersediaan bahan mentah yang dapat dikonsumsi oleh masyarakat ataupun dijual (Wulandari \& Budiono, 2016)

\section{Harga kopi codot yang stabil}

Harga kopi codot yang ditawarkan KWT Himawari dalam kurun waktu 2017 - 2018 masih terbilang stabil, dimana rata-rata harga yang diterima petani berkisar antara Rp $30.000-\mathrm{Rp}$ 35.000/kg (biji kering). Kestabilan harga yang diberikan oleh KWT Himawari tidak terpengaruh oleh harga musim panen kopi petik biasa, sehingga hal ini dapat menjadi peluang untuk petani kopi codot. Menurut Bastara et al. (2015) harga yang diterima petani dengan nilai yang cukup stabil dapat menjadi pendukung kestabilan produksi.

\section{B.2 Ancaman}

\section{Cuaca yang tidak menentu}

Perubahan iklim berpengaruh pada musim panen, dimana bunga kopi akan berguguran akibat hujan sehingga produktivitas kopi berkurang. Jika produktivitas kopi menurun, maka codot tidak bisa memakan kopi dan menghasilkan kopi codot, sehingga jumlah produksi kopi codot akan berkurang atau terbatas. Nurlaeli (2018) menunjukkan bagaimana cuaca berpengaruh terhadap produktivitas tanaman kopi yang sedang berbunga. Mbow et al. (2014) 
berpendapat bahwa ketidakpastian iklim global yang disebabkan oleh pemanasan bumi dan terjadinya penebangan hutan, bencana alam seperti banjir, tanah longsor dan kekeringan dapat menjadi ancaman untuk pertanian.

2. Kompetitor jenis kopi lain yang cukup banyak

Beberapa jenis kopi lain, seperti: luwak, Aceh Gayo, Mandailing, dan Liwa merupakan pesaing kopi codot berdasarkan citarasa dan manfaatnya untuk kesehatan. Saat ini manfaat kopi codot belum teruji secara klinis di laboratorium, namun beberapa jenis kopi competitor di atas sebagian telah teruji. Manfaat suatu produk dapat menjadi nilai tambah untuk meningkatkan ketertarikan konsumen akan kebutuhan yang bisa didapatkan dari manfaat produk tersebut. Nalurita et al. (2014) berpendapat bahwa banyaknya jenis kopi menyebabkan terjadinya persaingan pemasaran produk kopi di masyarakat.

\section{KESIMPULAN}

Faktor-faktor internal yang mempengaruhi pengembangan nilai ekonomi kopi codot adalah: 1) lokasi geografis yang sesuai untuk tanaman kopi, 2) aksesibilitas yang mudah, 3) kualitas kopi yang baik, 4) teknologi produksi yang baik, 5) kurangnya pengetahuan manfaat kopi codot, dan 6) kurangnya naungan pada tanaman kopi. Faktor-faktor eksternal yang mempengaruhi pengembangan kopi codot yaitu: 1) perkembangan permintaan kopi codot yang pesat, 2) perkembangan teknologi informasi dan komunikasi yang pesat, 3) mitra usaha di luar Kabupaten Tanggamus yang cukup banyak, 4) harga kopi codot yang stabil, 5) cuaca yang tidak menentu, dan 6) kompetitor jenis kopi lain yang cukup banyak. Pengembangan nilai ekonomi kopi codot dapat dilakukan melalui peningkatan penyuluhan untuk menambah pengetahuan tentang manfaat dan keuntungan kopi codot, serta memperluas kemitraan dengan pihak swasta lainnya agar pemasaran dapat berkembang lebih pesat.

\section{DAFTAR PUSTAKA}

Abdulhaji, S., \& Yusuf, I.S. (2016). Pengaruh atraksi, aksesibilitas, dan fasilitas terhadap citra objek wisata Danau Tolire Besar di Kota Ternate. Jurnal Penelitian Humano, 7(2), 134148.

Bastara, D., Soetriono., \& Hapsari, D.T. (2015). Strategi pengembangan agroindustri kopi bubuk arabika pada berbagai skala usaha di Kabupaten Situbondo. Agritop Jurnal IImu-ilmu Pertanian, 14(2), 187-191.

Diwangkoro, E. (2017). Tingkat kepuasan konsumen terhadap kualitas kopi dan kualitas pelayanan di Kafe Kopi Garasi Candi Winangun Ngaglik Sleman Yogyakarta. Jurnal Pendidikan Teknik Boga, 6(2), 1-8.

Febryano, I.G. (2008). Analisis finansial agroforestri kakao di lahan hutan negara dan lahan milik. Jurnal Perennial, 4(1), 41-47.

Febryano, I.G., Suharjito, D., \& Soedomo, S. (2009). Pengambilan keputusan pemilihan jenis tanaman dan pola tanam di lahan hutan negara dan lahan milik: Studi kasus di Desa Sungai Langka, Kecamatan Gedong Tataan, Kabupaten Pesawaran, Provinsi Lampung. Forum Pascasarjana, 32(2), 129-141.

Hairiah, K., \& Ashari, S. (2013). Pertanian masa depan: Agroforestri, manfaat, dan layanan lingkungan. In: Kuswantoro, D.P., Widyaningsih, T.S., Fauziyah, E., \& Rachmawati, R. (eds). Seminar Nasional Agroforestri; Malang 21 Mei 2013. Malang: Balai Penelitian Teknologi Agroforestri. pp. 23-35. 
ling, S., Sakiroh., \& Eko, H.P. (2012). Pengaruh jenis tanaman penaung terhadap pertumbuhan dan persentase tanaman berbuah pada kopi arabika Varietas Kartika1. Buletin Ristri3, 3(3), 217-222.

Incamilla, A., Arifin, B., \& Nugraha, A. (2015). Keberlanjutan usahatani kopi agroforestri di Kecamatan Pulau Panggung Kabupaten Tanggamus. Jurnal IIA, 3 (3), 260-267.

Joko, N.W.K., Lumbanbatu, J., \& Rahayoe, S. (2009). Pengaruh suhu dan lama penyangraian terhadap sifat fisik-mekanis biji kopi robusta. Seminar Nasional Perhimpunan Ahli Teknik Pertanian Mataram; Mataram, 8 - 9 Agustus 2009. pp. 217-225.

Kaskoyo, H., Mohammed, A., \& Inoue, M. (2017). Impact of community forest program in protection forest on livelihood outcomes: A case study of Lampung Province, Indonesia. Journal of Sustainable Forestry, 36(3), 250-263.

Kementerian Lingkungan Hidup dan Kehutanan (2016). Peraturan Menteri Lingkungan Hidup dan Kehutanan No. P.83/2016 tentang Perhutanan Sosial.

Mbow, C., Smith, P., Skole, D., Duguma, L., \& Bustamante, M. (2014). Achieving mitigation and adaptation to climate change through sustainable agroforestry practices in Africa. Current Opinion in Environmental Sustainability, 4(6), 8-14.

Nalurita, S., Asmarantaka, W, R., \& Jahroh, S. (2014). Analisis daya saing dan strategi pengembangan agribisnis kopi Indonesia. Jurnal Agribisnis Indonesia, 2(1), 63-74.

Nurlaeli, R. (2018). Strategi Pengembangan Agribisnis Kopi Arabika di Kabupaten Banjarnegara Jawa Tengah [Skripsi]. Departemen Agribisnis Fakultas Ekonomi dan Manajemen, Institut Pertanian Bogor.

Saragih, B. (2010). Paradigma Baru Pembangunan Ekonomi Berbasis Pertanian. Bogor: IPB Press. p. 289.

Sarma, P.K. (2014). An agribusiness development approach of beef cattle in selected aeas of Bangladesh. Journal Bangladesh Agril, 12(2), 351-358.

Sitanggang, J.N.T., \& Sembiring, S.A. (2013). Pengembangan potensi kopi sebagai komoditas unggulan kawasan agropolitan Kabupaten Dairi. Jurnal Ekonomi dan Keuangan, 1(6), 3448.

Supriatna, S., \& Aminah, M. (2014). Analisis strategi pengembangan usaha kopi luwak. Jurnal Manajemen dan Organisasi, 5(2), 228-242.

Wulandari, C. (2011). Agroforestry: Kesejahteraan Masyarakat dan Konservasi Sumberdaya Alam. Bandar Lampung: Universitas Lampung. p. 38.

Wulandari, C., Budiono, P., Yuwono, S.B., \& Herwanti, S. (2014). Adoption of agro-forestry patterns and crop systems around Register 19 Forest Park, Lampung Province, Indonesia. Jurnal Manajemen Hutan Tropika, 20(2), 86-93.

Wulandari, C., \& Inoue, M. (2018). The Importance of social learning for the development of community based forest management in Indonesia: The case of community forestry in Lampung Province. Journal Small-scale Forestry, 17(3), 361-376.

Wulandari, C., \& Budiono, P. (2016). Social capital status on community forestry (hutan kemasyarakatan) development in Lampung. International Journal of Forestry Research, 3(3), 21-22.

Yuwariah, Y. (2015). Potensi agroforestri untuk meningkatkan pendapatan, kemandirian bangsa dan perbaikan kualitas lingkungan. In: Rachman, E., Kusumawardhana, D., Widyaningsih, T.S., \& Kuswantoro, D.P. (eds). Prosiding Seminar Agroforestri; Bandung, 19 November 2015. Ciamis: Balai Penelitian Teknologi Agroforestri. pp. 3-21. 